\title{
De género y espacios (contenedores): hacia una deconstrucción de lo doméstico
}

\author{
About Gender and (Storage) Spaces: \\ towards a Deconstruction of Domestic Realm
}

\section{RESUMEN}

Tras analizar la dialéctica entre espacio (urbano y arquitectónico) y (el reparto asimétrico de los roles generizados en el seno de la familia), el artículo se centra, en primer lugar, en las repercusiones urbanas y arquitectónicas de la evolución de nuevas estructuras de convivencia en la contemporaneidad y, en segundo lugar, en la (r)evolución de la relación entre arquitectura y mobiliario/equipamiento, con un enfoque específico en los espacios contenedores, que se convierten en un pretexto para reflexionar sobre las prácticas domésticas contemporáneas, para preguntarse si, de cara al futuro, retomar el enfoque materialista feminista que priorizaba una reestructuración del tiempo y la visibilización de la labor doméstica y de las vivencias de la cotidianidad puede proporcionarnos nuevas claves interpretativas y guiarnos hacia nuevos paradigmas habitacionales, trayendo ventajas para toda la sociedad.

Palabras clave: género, domesticidad, vivienda, tiempo, mobiliario, almacenaje.

\begin{abstract}
After analyzing the dialectic between (urban and architectural) space and (the asymmetric distribution of gendered roles within the) family, the article focuses, first of all, on the urban and architectural repercussions of the evolution of new cohabitation structures in contemporary society and, secondly, on the (r)evolution of the relationship between architecture and furniture/equipment, with a specific focus on storage spaces, which become a pretext to reflect on contemporary domestic practices, and to wonder whether, facing the future, the feminist materialist approach that prioritized a restructuring of time and the visibility of domestic work and everyday life can be resumed to provide us with new interpretive keys and guide us towards new housing paradigms, bringing advantages for all society.

Keywords: Gender, Domesticity, Housing, Time, Furniture, Storage.

\section{SUMARIO}

-- El espacio doméstico como heterotopía patriarcal .-Hacia una domesticidad expandida -- Hacia una casa sin género ni jerarquía .- (Sin) Conclusiones: más allá de la relación entre arquitectura y mobiliario .- Referencias y bibliografía.
\end{abstract}

\section{El espacio doméstico como heterotopía patriarcal}

En una encuesta exploratoria realizada en el año 2000 por el Grupo de género y salud pública de SESPAS -en la que se planteaba la pregunta «describe los tres 
primeros pasos que realizarías para arreglar un armario» utilizando intencionalmente el verbo arreglar por su propia ambigüedad ${ }^{2}$ - sobre 92 respuestas, el $63 \%$ de los hombres describieron cómo se repara un armario, mientras que el 85\% de las mujeres contestaron explicando cómo ordenarían un armario. Evidentemente, cada una de las personas involucradas en el cuestionario ha contestado «en función de la actividad que más frecuentemente realiza» (Peiró, Colomer et al., 2000: 408) y -a pesar de que algunas de ellas se diesen cuenta de que la pregunta estaba mal redactada (por generar un posible malentendido)- en función de la influencia que los estereotipos de género existentes (asumidos casi de manera inconsciente) tienen en los patrones de socialización (incluso en el uso del lenguaje) de hombres y mujeres.

A ciertos espacios y objetos (contenedores) se suele asociar el trabajo doméstico que habitualmente las mujeres realizan. El espacio de la casa nunca ha sido neutro, es decir «sin atributos» (Fonseca Salinas, 2014: 84). Nuestra manera de entender la dimensión doméstica -y nuestros conceptos de intimidad, domesticidad, privacidad, intrusión, exclusión, segregación, confinamiento, invitación- surgió en Holanda en el siglo XVII, tal y como nos enseña tanto el famoso cuadro del pintor Peter de Höoch, El armario de la ropa blanca (1663) -en el que dos mujeres en primer plano ordenan un armario guardando cuidadosamente la ropa limpia- como toda la pintura holandesa de género. A medida que el desorden del espacio doméstico medieval cedía el paso a una progresiva diferenciación entre los espacios privados y los espacios públicos, entre el ámbito de la familia y el ámbito de las relaciones sociales (la ciudad, la calle, etc.), el espacio doméstico del hogar se convertía en el símbolo de un clima cultural basado en la devoción calvinista por el trabajo y por una vida austera y serena (que fortaleció un subjetivismo individual conservador y hogareño y un reparto de roles entre los miembros de la familia). La aparición de las primeras viviendas de alquiler en el siglo XVII facilitó esta situación y fortaleció la división entre lugar de trabajo y de residencia. Tal y como destaca Carmen Espegel Alonso (2016), la vivienda medieval era un lugar público más bien que privado, donde vivían muchos inquilinos a la vez (no necesariamente vinculados por lazos de consanguinidad), donde se combinaban residencia y trabajo, y donde parcas piezas de mobiliario, multifuncionales y trasladables, amueblaban las grandes salas donde se comía, se trabajaba, se recibía a los invitados, se negociaba, y, de noche, se dormía.

La idealización de la vida doméstica llevada a cabo en la pintura de género citada anteriormente confinó y relegó a la mujer al ámbito doméstico. Sin embargo, el complejo sistema de espacios intermedios (los de los patios y de los umbrales) que se articulan en secuencias espaciales dotadas de varios niveles de privacidad, y que enmarcan las escenas domésticas tan magistralmente retratadas en esas mismas obras de arte, demuestra que, por lo menos al principio, la privacidad del hogar seguía conectándose con la dimensión colectiva de la ciudad y de las calles. Poste-

2 El verbo arreglar, según el Diccionario de Uso de la Lengua María Moliner, puede tener varias acepciones, entre las cuales "poner las cosas limpias y en orden o como deben estar, se necesitan o se convienen» (Peiró, Colomer et al., 2000: 408) y «apañar, aviar, componer, modificar algo que no estaba correcto para que lo esté» (Peiró, Colomer et al., 2000: 408). 
riormente, con el ascenso de la clase media burguesa, los hogares superpoblados desaparecieron ${ }^{3}$ y el aprendizaje, llevado a cabo en lugares como los gremios o los talleres artesanales, fue sustituido por la educación formal. Todo esto provocó una mayor presencia de los hijos en casa, consolidando, por un lado, la relación con los padres, y, por el otro, una acepción de la familia como estructura social asimétrica que desde entonces ha dificultado que se contemplen otros patrones relacionales.

Del mismo modo, cualquier definición de domesticidad se ha combinado y fusionado con este tipo de relaciones familiares. La domesticidad como sinónimo del ámbito privado de la estructura familiar pequeñoburguesa es un producto y una construcción del incipiente capitalismo de principios del siglo XIX. Sus orígenes, que remontan a la época victoriana, cuando se iba formando tanto la familia burguesa como sus espacios domésticos especializados, están arraigados en un específico sistema de poder y en una cultura que se formalizó entre el final del siglo XIX y comienzos del siglo XX. Desde entonces, la separación entre hombres y mujeres, que se ha convertido en algo estructural a lo largo de los siglos, se ve enmascarada por el reconocimiento formal de los derechos que, en la realidad de los hechos, no han cambiado todavía de manera profunda las prácticas cotidianas, sociales y de vida.

Si seguimos viviendo en espacios domésticos que desde el siglo XIX han evolucionado muy poco, estamos perpetuando y legitimando, en la reiteración de ciertas pautas y en la articulación de los espacios de la vivienda, unas estructuras jerárquicas y de poder que reflejan el androcentrismo de una sociedad patriarcal que ignora la complejidad de la situación actual (y la evolución de nuevas estructuras familiares que en la contemporaneidad ya se están produciendo) y que normalizan algunos modelos comportamentales (como los representados por el matrimonio, las viviendas unifamiliares suburbanas y la propiedad privada) como conditio sine qua non para la aceptación social y el éxito, naturalizando la exclusión y las relaciones de subordinación y opresión. Personas solteras, familias monoparentales, parejas sin hijos, personas (sobre todo mujeres) que han sufrido violencia doméstica, son sólo algunas de las estructuras de convivencia que ya no se pueden identificar con las familias nucleares tradicionales y que necesitan un cambio de paradigma en la manera de entender y construir los espacios en los que vivimos. De hecho, viviendas para grupos, o viviendas entendidas como lugares de paso y de uso temporal -ya que la movilidad y flexibilidad (e incertidumbre) laboral (y social) nos obliga a plantearnos nuestras vidas de manera distinta- son solo unas de las posibles fronteras de una nueva manera de entender la domesticidad que impulsa hacia nuevos desarrollos y desemboques espaciales. Vaciada de sus contenidos (simbólicos, es decir los relacionados a la familia nuclear), entonces, ¿qué es la vivienda y quién vive en ella? ¿El espacio doméstico se urbaniza y/o el espacio urbano se domestica?

En tanto que artefacto, la arquitectura (a varios niveles y escalas) es al mismo tiempo producto y medio (véase Rendell, 2009: 101-102): no solo es el resultado de un proceso de construcción sino también el contexto en el que se construye, incluidos

3 A pesar de esto, hay que esperar hasta el siglo XVIII para encontrar habitaciones privadas, es decir ámbitos espaciales en la misma casa destinados a específicos momentos de la vida: hasta entonces, «la promiscuidad era monoespacial» (Espegel, 2016: 32). 
todos sus condicionantes. Y no se trata de un artefacto cualquiera, sino más bien de algo en el que se cristalizan, incrustan y aglutinan discursos y representaciones, que precisamente por medio y a través del artefacto se (re)producen, se repiten y se perpetúan, convirtiéndose en patrones espaciales que consolidan y soportan los roles de género, tanto en el ámbito público como en el privado.

La historia reciente ha demostrado que, mientras algunos espacios de la vivienda, los más vinculados a la técnica, a lo maquinico (como cocina, baño, instalaciones) han ido evolucionando convirtiéndose en el campo privilegiado donde se han investigado y experimentado las relaciones entre la vida privada y el medio técnico (Herreros, 2010), los espacios domésticos que están más vinculados a una dimensión simbólica y representativa (como salones y comedores) o asociados a la idea de privacidad e intimidad (como dormitorios, espacios de almacenaje, etc.) se han estancado y se han mantenido casi estáticos, a pesar de que, gracias a los avances de las tecnologías interactivas y virtuales, las funciones que antes eran realizadas por las propias habitaciones y por espacios específicos pueden ser desempeñadas por objetos dispersos en un espacio sin jerarquías. La vivienda, el hogar y el espaciotiempo doméstico no terminan donde comienza la ciudad y viceversa. Pero estas condiciones ¿son compartidas de manera uniforme e igualitaria entre hombres y mujeres? A pesar de que en principio facilitan, por un lado, la superación del mismo concepto de escala, hacia un nuevo estatuto trans-escalar de los objetos mismos (Herreros, 2010), y, por el otro, posibilitan la disolución de los límites entre lo público y lo privado, lo urbano y lo doméstico (incluso entre día y noche, o trabajo y ocio), en la realidad de nuestras vidas cotidianas queda todavía mucho por hacer, si las estadísticas demuestran que la brecha de género en el tiempo dedicado a las tareas domésticas y familiares es todavía muy ancha. «De media, las mujeres dedican el doble de tiempo que los hombres a este trabajo no pagado en los países de la OCDE, la organización de países desarrollados» (Sánchez, 2017).

El hogar de la familia nuclear se ha convertido entonces en una fortaleza impenetrable y sagrada, una heterotopía simbólica -entendida como enclave y espacio de exclusión con acceso limitado- depositaria del mundo y de la ideología heteropatriarcal, construida histórica y culturalmente. Parafraseando a Michel Foucault, todavía no se ha logrado aquella des-santificación ${ }^{4}$ de la vivienda unifamiliar que es sumamente necesaria para que la sociedad se deshaga de cualquier imaginario binario y se llegue por fin a una erosión progresiva de las categorías identitarias.

\section{Hacia una domesticidad expandida}

La especialización de los espacios domésticos, como reflejo de la perpetuación de las jerarquías sociales generizadas, constituye, tal y como se ha afirmado en el párrafo anterior, una forma de «salvaguardia cultural» (Marinas Sánchez, 2004: 208) de un sistema de valores que la sociedad y la cultura consideran como «variables

4 «[P]ublic and private space, family and social space, cultural and utilitarian space, the space of pleasure and the space of work -all opposites that are still actuated by a veiled sacredness» (Foucault, 1997: 331). 
independientes» (Marinas Sánchez, 2004: 206), y que por tanto se resiste a cambiar porque en ellos se fundamenta lo cotidiano. Sin embargo, ciertas condiciones impuestas por las exigencias de flexibilidad de las nuevas generaciones conllevan como consecuencia la necesidad de un cambio de paradigma (espacial y temporal a la vez). La división (obvia y aparentemente inocua) entre el hogar y el lugar de trabajo ha sido la base sobre la que se ha construido nuestra sociedad moderna. Nancy Duncan (1996) da una definición bastante exhaustiva de los dos ideales que surgieron como consecuencia de esta división (es decir, lo privado, por un lado, y lo público, por el otro), destacando la combinación/fusión entre lo privado y lo doméstico en oposición a lo público, que creó y apoyó la brecha de género entre (la feminización del) interior y (la masculinización del) exterior. Los espacios funcionales de la casa (como las cocinas, las despensas, los espacios de almacenamiento, etc.) han sido, por tanto, tradicionalmente asociados a la figura femenina y a ciertas ideas de privacidad y domesticidad. Ahora que los límites entre espacio público y espacio privado, entre interior y exterior, que hasta hace algunos años seguían coincidiendo con los límites entre lo doméstico y lo urbano, se están difuminando (especialmente con la llegada de internet y, a partir del año 2000, de las redes sociales), hay que replantearse las cosas de manera distinta.

Remedios Zafra (2010) destaca la situación de convivencia en la que se encuentran dos tendencias opuestas de la contemporaneidad y que están planteando otra idea de lo doméstico: «no es tanto una sustitución y oscilación lineal entre estas dos tendencias, sino la convivencia de ambas como característica de un mundo globalizado» (Zafra, 2010: 27-28). La movilidad ya no es el reverso del estar en o volver a casa, $\mathrm{y}$, de la misma manera, la domesticidad ya no requiere necesariamente la ausencia de movilidad: se está desarrollando algo distinto, otro escenario, el de un «cuarto propio conectado» (Zafra, 2010), cuyos límites difuminados están hechos de espacio y de tiempo. Tal y como subraya Beatriz Colomina (citada en: Hernández Martínez, 2016), todo esto tiene repercusiones e implicaciones muy profundas en nuestra manera de vivir los espacios que hemos heredado de la modernidad. La actitud universalista y funcionalista del Movimiento Moderno ya no es una postura viable frente a los desafíos de la sociedad contemporánea. Desde ciertos puntos de vista, hemos vuelto, gracias a nuestros móviles y tabletas, a una condición premoderna, en la que en la cama se hacía de todo. Se abre una nueva frontera del estar en casa estando (y siendo) en el mundo: el espacio-tiempo doméstico es cada vez más urbano y se expande en la ciudad. Ya no necesitamos los espacios tradicionales de la vivienda, que se pueden remplazar con otros tipos de espacios que externalizan algunas de (o todas) las actividades de nuestras rutinas cotidianas: en los gimnasios cuidamos de nuestros cuerpos, nos duchamos, y hacemos ejercicio físico; en los bares y restaurantes comemos; en nuestros ordenadores portátiles, en los móviles, en las tabletas leemos y/o guardamos nuestros libros en formato digital; en el maletero del coche, o en nuestros bolsillos, o en las taquillas de nuestra oficina almacenamos nuestras pertenencias (véase López Sánchez, 2015: 129). Cuando actividades tradicionalmente alojadas en el marco de un interior doméstico se eliminan de la casa, no solo la configuración espacial dentro de la casa, sino también el tiempo 
dedicado a estas actividades se altera, y el sentido de lo que un hogar debe incluir o ser cambia por completo. La interacción entre la escala doméstica y la urbana se hace más fluida a través del tiempo y del espacio, así como la relación entre lo privado y lo público en el hogar. Estas condiciones tienen el potencial para desestabilizar tanto los dualismos generizados (espacios productivos vs espacios reproductivos) como el terreno ya multifacético y complejo del debate arquitectónico contemporáneo con respecto a las formas de pensar y proyectar viviendas y ciudades. Sin embargo, en este momento no nos permiten asumir todos los retos que las condiciones reales de las ciudades en las que vivimos y trabajamos plantean. De hecho, si, en principio, ya existen las premisas para que el sujeto nómada contemporáneo pueda sentirse como en casa en cualquier lugar, estas mismas condiciones -cuya accesibilidad se ve todavía condicionada y limitada por cuestiones de género, raza, clase, prácticas sexualespueden aumentar aún más la brecha entre colectivos (minoritarios) y entre quienes pueden acceder a ellas y quiénes no.

El nomadismo filosófico de Rosi Braidotti (2006), concebido como categoría interpretativa del sujeto postindustrial, abarca la condición nómada tanto en la ciudad global (movilidad como posibilidad voluntaria) como en los campos de refugiados (movilidad como necesidad involuntaria), que ella define como "two sides of the same global coin» (Braidotti, 2006: 60), enfatizando la dimensión esquizoide de las economías globales. La contribución que este punto de vista podría brindar a nuestra cultura contemporánea habitacional es muy valiosa y podría abrir nuevas posibilidades para la gestión de los entornos domésticos y urbanos. El nomadismo al que se refiere Braidotti no ignora la localidad, sino que establece con ella una relación tentativa, cambiante, dinámica y temporal, lo que implica que el nómada tiene que renegociar continuamente su relación con el contexto, participando activamente en su construcción, moldeándolo y siendo a su vez moldeado por medio de prácticas socioespaciales que activan un sentido de pertenencia y de responsabilidad compartida -una «nomadic eco-philosophy of multiple belongings» (Braidotti, 2006: 123)- más bien que mecanismos de apropiación. De esta manera, la renegociación del espacio doméstico se puede enmarcar en el ámbito ético y estético de un proceso social y cultural más amplio, vinculado al medioambiente, al territorio, a las recaídas locales de sistemas y redes de relaciones transnacionales, en el que hay que redefinir y replantear los vínculos de parentesco, el concepto mismo de propiedad, los métodos de proyectos convencionales y todas las estrategias (incluidas las de acceso a la vivienda) y los patrones normalizados y tipificados de un modelo hegemónico que hasta la fecha ha marginado discursos y posturas minoritarias, resultando más eficaces «en su mercantilización que en su vocación de servicio» (Serrano-Lanzarote, Mateo-Cecilia y Rubio-Garrido, 2016).

Si todavía las mujeres dedican a las labores domésticas mucho más tiempo que los hombres, es evidente que ese colectivo no puede participar en todos los cambios del espacio-tiempo doméstico-urbano mencionados anteriormente y gozar de sus beneficios en condiciones de igualdad. Por esta misma razón, es preciso preguntarse si, de cara al futuro, retomar el enfoque materialista feminista que priorizaba una reestructuración del tiempo y la visibilización de la labor doméstica y de las vivencias de la cotidianidad 
podría efectivamente proporcionarnos nuevas claves interpretativas y guiarnos hacia nuevos paradigmas habitacionales, trayendo ventajas para toda la sociedad.

\section{Hacia una casa sin género ni jerarquía}

Muchas teóricas feministas, como Doreen Massey, han demostrado que la oposición binaria entre lo público y lo privado no es apta para definir el lugar llamado hogar, ya que ha sido siempre, de una forma $\mathrm{u}$ otra, "open; constructed out of movement, communication, social relations which always stretched beyond it» (Massey, 1992: 13). Dolores Hayden afirmaba ya en los años 70 -haciendo referencias específicamente al modelo urbanístico de las ciudades americanas de finales del siglo XX que había convertido en entornos construidos la división sexual del trabajo, dándole una legitimación tanto en la forma como en la imagen de una ciudad caracterizada por áreas residenciales suburbanas segregadas, conectadas unas a otras por medio de autopistas y centros comerciales- que:

... el único remedio para esta situación es desarrollar un nuevo paradigma de casa, de barrio y de ciudad, para empezar a definir el diseño físico, social y económico de los asentamientos humanos que contribuyan a apoyar, más que limitar, las actividades de las mujeres trabajadoras y de sus familias (Hayden, 1979).

Hayden elaboró, por tanto, una propuesta alternativa que planteaba una remodelación radical de los suburbios estadounidenses (y de sus millones de viviendas unifamiliares), la de HOMES (Homemakers Organization for a More Egalitarian Society), basada en la presencia de servicios comunitarios compartidos (cocinas, guarderías, lavanderías, jardines comunitarios, etc.) y caracterizada por un enfoque novedoso. "All services would be run like business available to customers in addition to the members of the community» (Torre, 1999: 38) y, cosa aún más importante, «the collective activities would generate at least thirty-seven jobs for the residents» (Torre, 1999: 38). A nivel arquitectónico, Hayden propuso la posibilidad de convertir los espacios y estructuras auxiliares (como los cobertizos, los garajes, los porches) -que abundan en los jardines delanteros y/o traseros de las viviendas unifamiliares americanas en servicios comunitarios compartidos «turning the block inside out» (Torre, 1999: 38), abriendo nuevas fronteras del urbanismo que aún quedan por explorar. ${ }^{5}$ Sin embargo, se necesita, en primer lugar, un replanteamiento del concepto de propiedad

5 Si bien basados en premisas completamente diferentes, el proyecto Backyard Homes ha demostrado que a través de pequeñas manipulaciones del entorno construido existente se pueden lograr grandes cambios. Promovido por el cityLAB, un think tank de la UCLA School of the Arts and Architecture, el proyecto ha conseguido que muchos condados de California se enfrentaran con éxito al problema urgente de proporcionar a su comunidad unas viviendas asequibles que pudiesen mejorar su calidad de vida. A través de la suavización y flexibilización de las normas de edificación, se ha logrado una reinterpretación creativa de las así llamadas Granny Units gracias a la cual muchas familias han conseguido convertir sus garajes y patios traseros en fuentes de ingresos. Véase: Cuff, Dana, Higgins, Tim \& Dahl, Per-Johan (2010) Backyard Homes. Los Angeles: CityLAB, UCLA Department of Architecture and Urban Design. 
privada y, en segundo lugar, un marco político y jurídico adecuado que fomente el acuerdo entre vecinos para incentivar el desarrollo de planes de vivienda más flexibles y asequibles, junto con los consiguientes ajustes en el campo de las regulaciones de la planificación urbana (Blanchar, 2017). Un experimento interesante en este sentido es el proyecto La Borda que se está llevando a cabo en Barcelona; se trata de un modelo de vivienda en cesión de uso «donde la reinvención del derecho a la vivienda encuentra nuevas fórmulas de acceso y gestión comunitaria» (Blanchar, 2017). La presencia de servicios colectivos compartidos permite liberar espacio en las viviendas (aunque cada unidad tenga su propia cocina individual) y proporciona nuevos lugares de socialización. No se trata en sí de un enfoque espacial novedoso, ya que, en esta misma dirección, se desarrollaron varios experimentos e iniciativas en los años veinte del siglo pasado -como las viviendas mínimas obreras de la Viena Roja, el Heimhof (1921-1922) o el Karl-Marx-Hof (1926-1930), por ejemplo, donde nunca se ha considerado «la vivienda como elemento autónomo, autosuficiente, ni el lugar donde la familia desarrollaría toda su actividad» (Muxí, 2008: 21)- que intentaron externalizar de la vivienda, de manera aún más radical, todas aquellas actividades que, si compartidas, podrían haber supuesto una reducción de la carga laboral de la mujer en casa y del trabajo doméstico en general. Sin embargo, lo novedoso en La Borda es el enfoque del marco normativo y legal «que abre una alternativa al acceso a la vivienda, polarizado, [...] entre el alquiler y la compra» según afirma el concejal de Vivienda de Barcelona, Josep María Montaner. ${ }^{6}$

Witold Rybczynski destaca cómo la idea masculina de la casa ha sido «fundamentalmente sedentaria: la casa como refugio contra las preocupaciones del mundo, un lugar donde hallarse tranquilo» (Rybczynski, 1991: 166), mientras que la idea femenina de la casa ha sido más dinámica y relacionada con la comodidad, pero también con el trabajo doméstico (véase: Rybczynski, 1991: 166). No se está avalando, con esta aserción, un discurso esencialista «que proclama una diferencia básica (de esencia) entre hombres y mujeres que condicionaría sus respectivas creaciones» (Torrent Esclapés 1995: 57), más bien se quiere subrayar «la diferencia entre las producciones masculinas y femeninas [...] como producto inevitable de la distinta posición de los géneros en el ámbito de la cultura y, en general, de la vida» (Torrent Esclapés 1995: 57).

Por esta misma razón, las mujeres fueron «pioneras del "cientifismo" doméstico» (Espegel, 2016: 41). Catherine Esther Beecher -sin ni siquiera ser arquitecta (era maestra de escuela) ni revolucionaria o feminista, ya que en ningún momento cuestionó el sitio de la mujer en la sociedad de la época- presentó, en el libro The American Woman's House, publicado en 1869 y escrito junto con su hermana Herriet Beecher Stowe (más conocida por ser la autora del famoso La cabaña del tío Tom), un prototipo de casa en que se destaca la importancia de una planificación espacial

6 Véase: Redacción y agencias (2017, febrero 17) «Una cooperativa levanta en Barcelona el edificio de madera más alto de España». La Vanguardia. Recuperado en: http:/ / www.lavanguardia.com/ local/barcelona/20170216/4278496793/cooperativa-barcelona-levanta-edificio-madera.html [fecha de consulta: 13 de noviembre de 2017]. 
moldeada según principios ergonómicos y de eficiencia, en aras de facilitar las tareas domésticas y aligerar su carga. La atención reservada a ciertos principios espaciales de flexibilidad asombra por su modernidad: en el comedor de la planta baja de su prototipo, por ejemplo, un gran armario sobre ruedas, cambiando su colocación, podía convertir la misma habitación en un espacio para desayunar o para estar (creando zonas más pequeñas y acotadas, como la zona de costura) durante el día, y en un espacio para dormir, por la noche. A lo largo de la historia estos pequeños objetos y espacios contenedores, hayan sido o no solidarios con la arquitectura y con lo construido, han conformado el espacio y el tiempo de la mujer en casa. Y cuanto más la casa se encoje, más los armarios se convierten en elementos importantes para garantizar su adecuado funcionamiento y confort espacial. No es casualidad, por ejemplo, que Le Corbusier eligiese a una mujer, Charlotte Perriand, como asociada para que se ocupara de todo lo relacionado con el acondicionamiento de los espacios interiores de la casa moderna. Ella se encargó del estudio de los casiers, siendo una de «las grandes obsesiones de Le Corbusier [...] encontrar la forma eficiente de almacenaje que permitiera recoger en el interior distintos tipos de objetos, a la vez que eliminara divisiones innecesarias en un concepto de espacio unitario» (Cruz, 2008: 134). Perriand era consciente de que, al resolver el tema del almacenaje, siendo «factor de orden y armonía» (Melgarejo Belenguer, 2011: 219), se habría solucionado la cuestión de la necesaria renovación de la vivienda. Para que esto se cumpliera de manera más efectiva, sin embargo, se precisaba un cambio profundo en la sociedad y en la manera de vivir: el cambio habría tenido que afectar al núcleo básico de la misma sociedad, es decir, a la familia. Pero, a pesar de las buenas intenciones, arquitectura y sociedad no consiguieron sintonizarse y sincronizarse de manera eficiente.

«Vestimenta y mobiliario quedan ligados a la sociedad que enmarca su producción y su uso cotidiano. Ambos campos prolongan al individuo en su habitar. [...] Está relacionando el vestir con el almacenar. Vestimenta, mobiliario y stocage se complementan en el nuevo habitar acorde a los tiempos» (Moreno, 2017: 81). Precisamente por eso, pequeños ajustes en la distribución del espacio interior de la vivienda pueden conseguir muchas ventajas en la gestión no solo del espacio sino del tiempo de las actividades relacionadas con las labores domésticas, mejorando progresivamente la vida (de sus habitantes) en su dimensión cotidiana. La eliminación de la duplicación de funciones y la desaparición de espacios de almacenaje dispersos «en puntos disgregados, residuales o añadidos ad-hoc [...] que incrementa el recorrido desde un punto a otro [...] aumentando el tiempo necesario para su ejecución» (Valero, 2016: 159), son sólo algunos de los cambios propuestos y evidenciados por Zaida Muxí Martínez $(2009$, 2010), quien ha llevado a cabo numerosos estudios y talleres con el fin de alcanzar un modelo de casa sin género ni jerarquías espaciales. Estando las estrategias de convivencia en la sociedad contemporánea en permanente cambio -situación de la que las mujeres suelen pagar las consecuencias- es imprescindible no solo la existencia de cierta flexibilidad/ adaptabilidad en el espacio doméstico sino también la posibilidad de permitir y 
favorecer usos simultáneos. Una de las recomendaciones en la que Muxí insiste es la presencia en la vivienda de habitaciones con dimensiones similares o comparables para permitir usos genéricos, cosa que se puede conseguir evitando también la presencia de armarios en los dormitorios (desplazando los espacios de almacenaje en los pasillos que de esta manera pueden cobrar más protagonismo y pasan de ser espacios de conexión y/o residuales a ser espacios de uso) o de baños vinculados a los dormitorios, que crean jerarquías espaciales. Hay algunos ejemplos de viviendas sociales que, tal y como destaca Muxí (2010), han sido olvidados por la historiografía oficial, como la Casa de las Flores en Madrid (1931) del arquitecto Secundino Zuazo, en las que comedores y dormitorios casi tienen el mismo tamaño, creando espacios adaptables a las exigencias de sus habitantes y usuarios y liberados de la presencia de espacios de almacenaje, que se concentran en los pasillos (en forma de armarios empotrados). En semejantes marcos espaciales, las personas son las verdaderas protagonistas de las acciones que se realizan en las viviendas, más bien que los programas funcionales preconcebidos, o los muros o los muebles, tal y como afirma Josep María Montaner (2014: 27). «Program is up to the inhabitant to decide. Program is the result of a lived time, and an appropriated space» (Lai, 2008).

Lo que se cuestiona es exactamente la incapacidad de la vivienda contemporánea de configurarse como algo distinto de los modelos de las épocas anteriores, de actualizarse según las nuevas condiciones, de convertirse en un complejo espacio multicapas y multidimensional (siendo el tiempo, en términos de duración y simultaneidad, tan importante como sus espacios, tanto virtuales como mentales). Se precisan parámetros proyectuales basados en las experiencias, en los comportamientos más bien que en las funciones y en los estándares cuantitativos, lo cual es posible solo a través de enfoques multi- e inter-disciplinarios. «Interesa una arquitectura que trascienda su marco disciplinario y proponga nuevos sentidos de la domesticidad hoy: no tanto viviendas en sensu stricto; antes bien, "prácticas domésticas contemporáneas" (Serrano-Lanzarote, Mateo-Cecilia y Rubio-Garrido, 2016). Por su naturaleza, las prácticas domésticas contemporáneas son temporales, inestables, y dependen de las circunstancias, y pueden definitivamente convertirse en acontecimientos independientes de las características espaciales propias del contenedor arquitectónico. Este estatuto de autonomía respecto del espacio construido que adquieren tanto las actividades como los artefactos que permiten que un espacio pueda albergarlas, genera una verdadera revolución espacial y la inversión de la perspectiva tradicional (de lo general al detalle). La escisión entre casa y hogar está potencialmente ya en curso: la idea de domesticidad ya puede, en principio, quedar completamente desvinculada de la idea de casa y espacio doméstico. Por tanto, los muebles, las máquinas, la decoración, se convierten en aquellos «implementos añadidos» (Herreros, 2010: 153) que califican y especifican el espacio. El marco espacial arquitectónico estable y su funcionalidad quedan supeditados a una supervaloración de todos los aspectos (afectivos, hedonísticos, seductores más bien que funcionales) ligados a la percepción sensorial y al individuo, hacia un renovado papel del cuerpo y de las variables subjetivas (prácticas sexuales, hábitos culinarios, tiempo libre, trabajo, relación con los demás, etc.). 
Por un lado, la vivienda ya no es la única referencia para hacer ciudad, ya que los espacios, tanto habitacionales como de trabajo, descanso y ocio, ya no son unidades espaciales sino mentales -tal y como afirma Atxu Amann (2005:235) - soportados por sistemas de objetos dispersos en un espacio topológico (ya no geométrico) entendido como un espacio cuya organización y definición se basa en «la disposición conectiva de elementos y no en la fragmentación estable de actividades» (Herreros, 2010: 153). Por el otro lado, más bien que la familia en su sentido tradicional, es el individuo quien constituye el referente social alrededor del cual se concreta el espacio construido (Amann y Alcocer, 2005), siendo tanto el concepto de casa como el de lo doméstico algo más borroso, más subjetivo, provisional y movedizo (Markiewicz, 2015). Si es el sujeto, el individuo, el nuevo referente de un espaciotiempo doméstico que ya no es ni un contenedor ni un simple envoltorio, sino más bien un ámbito activado por las relaciones entre unas constelaciones de objetos y lxs usuarixs, el papel de la arquitectura y de lxs arquitectxs tiene que re-plantearse. De acuerdo con este renovado re-posicionamiento, las prácticas proyectuales y de diseño tienen que afinar nuevas estrategias y metodologías que incorporen herramientas y formatos que puedan proporcionar toda la información posible sobre las vivencias de esxs usuarixs. Sobre todo en estos tiempos de crisis financiera global hay que volver a cuestionar la efectividad en la contemporaneidad de los patrones y modelos desarrollistas que han provocado la creciente saturación del mercado inmobiliario, empezando a atender a las exigencias de colectivos singularizados (monoparentales, homoparentales, multiculturales, con movilidad reducida...) (Serrano-Lanzarote, Mateo-Cecilia y Rubio-Garrido, 2016), cuyas necesidades han sido hasta ahora ignoradas.

\section{(Sin) Conclusiones: más allá de la relación entre arquitectura y mobiliario}

A través de varias estrategias formales y soluciones tecnológicas apropiadas, es ahora técnicamente viable y posible desvincular el espacio de la vivienda de los espacios de servicios tradicionales determinados por la presencia de las bajantes y montantes verticales de las instalaciones, que ahora se pueden desviar horizontalmente gracias al espesor de los forjados, permitiendo la movilidad no solo del mobiliario, sino también de los baños y cocinas, para dejar máximo protagonismo al usuario final de la vivienda (véase Valenzuela, 2004). Estos asuntos se habían ya planteado en propuestas sobre viviendas como las del antiguo estudio de Iñaki Ábalos y Juan Herreros, precisamente en su proyecto ganador de un accesit en el concurso Vivienda y ciudad que organizó en 1988 la revista Quaderns d'arquitectura $i$ urbanisme. En este ejemplo, que representa un cambio de paradigma y una ruptura radical con casos anteriores, el espacio de almacenaje se distribuye perimetralmente en una franja de armarios que liberan por completo la planta, y el espacio entre los dos planos horizontales del suelo y del techo «queda, de este modo, vacío para ser utilizado. Un vacío que se pone en evidencia al sugerir que la casa se coloniza -más que se ocupa en un sentido tradicional» (Monteys y Fuertes, 2014: 65). 
Sin embargo, la reformulación del espacio doméstico, que pasa necesariamente por la reconfiguración de la relación entre arquitectura y mobiliario -que se convierte en equipamiento (Cruz, 2008: 139) y, más bien que ocupar espacios, define ámbitos- y la subversión de sus prácticas de uso, puede remontarse al aporte de Charlotte Perriand, esa joven que, en 1927, recién salida de la Escuela de Artistas Decoradores de París, expuso en el Salón homónimo el Bar sous le toit, es decir la reproducción del bar que había diseñado para el salón de su propia casa, demostrando un planteamiento novedoso del espacio doméstico: en primer lugar, porque un «bar es un espacio que, en el principio del siglo XX no se encontraba en casa de nadie» (Cruz, 2008: 138) y, en segundo lugar, por la elección de los materiales (ya que los brillos y los reflejos del aluminio parecen desmaterializar las piezas) y por la posibilidad de interactuar con el mobiliario. Al año siguiente (en 1928), en el Salon des Artistes Décorateurs, presentó una de sus patentes más importantes, es decir la mesa extensible y deslizante compuesta por una lámina de neopreno dotada de un alma de madera que se enrolla en una caja en el costado de la misma mesa, cuya segunda versión fue fabricada por Thonet en 1930 (aunque nunca llegó a comercializarse). Por banal o irrelevante que pueda parecer, esa mesa demuestra su voluntad de deshacerse de convenciones y costumbres, eliminando la necesidad del uso del mantel.

También en los proyectos elaborados conjuntamente por Mies Van der Rohe y Lilly Reich -ya a partir del Café de terciopelo y seda realizado en ocasión de la exposición de Die Mode der Dame en Berlín en 1927- la relación espacio-mobiliario y arquitectura-decoración se tradujo en un nuevo concepto de espacio interior, en cuya definición cobran protagonismo las calidades espaciales del vacío y los colores y propiedades de los materiales. Reich pareció darse cuenta «de la capacidad de transformación que encierran las cosas pequeñas» (Gutiérrez Mozo, 2011: 17) y que una renovación de la arquitectura desde el interior podía enfrentarse a los retos planteados por los cambios sociales. De hecho, para la exposición de Berlín Deutsche Bauausstellung, sección Die Wohnung Unserer Zeit (1931) diseñó (junto a Mies en el caso del «Apartamento para un soltero») dos viviendas mínimas contiguas basadas sobre dos programas funcionales poco convencionales para aquella época, es decir una casa para una persona sola y una para una pareja casada sin hijos, vinculados a una premisa espacial fundamental: la utilización de servicios comunes externos a las viviendas. El bloque compacto y exento del armario-cocina se configura como el principal elemento de compartimentación espacial, cuyos detalles diseñó con precisión según el tamaño de los utensilios que debía almacenar.

La dedicación de una atención especial a estos tipos de espacios demuestra la importancia que estas autoras concedían a esas piezas de la casa, a estos elementos mínimos, los armarios, que en sus manos pasaban de ser:

... el símbolo de las tareas domésticas de la mujer al elemento utilizado por la mujer para transformar la estructura de la vivienda y desde ahí poder plantear un nuevo tipo de relaciones espaciales y con ellas un cambio en la relación entre los habitantes (Melgarejo Belenguer, 2011: 227-28). 
Más bien que «educar» al usuario sobre el uso de nuevos espacios, los proyectos de estas autoras recorren el camino inverso: los espacios se tienen que adaptar a sus nuevos usuarios. Los interiores de las dos casas de Eileen Gray -la Maison en Bord de Mer o E.1027 (1926-1929) y Tempe à pailla (1932-34)- se basan incluso en algo más de eso, ya que todos los elementos (mobiliario, acabados, materiales, muros, ventanas), que suelen contribuir a la definición espacial, interactúan con los usuarios para crear un conjunto espacial cambiante, modificable en cualquier momento. Con su arquitectura de relaciones, materialidad y estratificación espacial nos enseña que otra manera de concebir la modernidad es posible, yendo más allá de las «cold calculations» (Gray, cit. en Constant, 2000: 238) de la arquitectura moderna, incluyendo el cuerpo y el tiempo en el espacio. «The connection between bodies and things is an essential avenue of exploration for critical studies of the interior, and the body is itself arguably a thing, simultaneously creating and formed by its environment» (Griffith Winton, 2013: 46). La manera de ser arquitecto de Eileen Gray -una mujer que, sin que fuese formada oficialmente como arquitecta (ya que en este ámbito fue autodidacta), había conseguido alcanzar una interpretación propia de la modernidad, anti-heroica, anti-canónica, basada en la sensualidad de los materiales y sus texturas, en un espacio no antropocéntrico en el que el ser humano se siente parte integral del conjunto, más bien que su centro- era diferente. Su búsqueda de lo íntimo en lo moderno, la ambigüedad de los espacios interiores de sus casas, que esconden y revelan, proponen de hecho una nueva manera de ser modernos y de vivir, más allá de los códigos heterocéntricos y heteronormativos. Su arquitectura multicapas exige una lectura muy atenta, que va más allá de la dicotómica distinción entre muros y filtros, entre suelos y alfombras, entre muebles y arquitectura, entre decoración y edificio.

Bonnevier (2007) interpreta la casa E.1027, diseñada por Gray para sí y su pareja (en aquel entonces, el arquitecto y editor Jean Badovici), como una «architecture of a nonstraight position» (Bonnevier, 2007: 43), es decir como el reflejo espacializado de su manera anticonvencional de vivir su (bi- y homo-) sexualidad. "Gray's sliding sexuality» (Bonnevier, 2007: 43) la llevó a huir de las convenciones sociales que le exigían que fuera esposa y madre. Sobre todo en la E.1027 los límites entre mobiliario y arquitectura han sido borrados -y lo mismo se puede decir de los márgenes del concepto espacial tradicional de habitación- generando interconexiones espaciales, márgenes borrosos entre interior y exterior, espacios divisibles y separables temporalmente, donde autonomía y privacidad siempre están al alcance de los usuarios sin restar libertad y posibilidad de cambio según las exigencias y las circunstancias.

Tempe à pailla, realizada a partir de una estructura pre-existente, se configura como un sistema de agregación por partes que sin embargo no se perciben como entidades fragmentadas sino más bien, gracias a la adopción de múltiples y variados dispositivos de definición espacial -cambios de cuotas y desniveles, piezas de mobiliario que cambian su configuración en el espacio (como el armario extensible en aluminio que representa el límite inestable entre la habitación de Gray y su baño) según las exigencias de uso, techos convertidos en contenedores y espacios 
de almacenamiento, escaleras disimuladas por una banqueta, etc.- como articulaciones diferenciales de un único espacio, realizado «a medida».

En ambas casas, los espacios de almacenamiento nunca tienen esta única función, más bien están siempre incorporados, ocultados, disimulados en otros dispositivos espaciales, desdoblando su funcionalidad. Por citar algunas de sus mejores piezas, las escaleras de acceso a la cubierta de la Maison en Bord de Mer gracias a su cerramiento transparente se convierten en un espacio contenedor $y$, a la vez, en un lucernario, que ilumina este espacio. Ya en los sofisticados dispositivos de almacenaje empotrados en el falso techo del apartamento de Jean Badovici en Rue de Chateaubriand -una pequeña pieza de tan sólo 40 metros cuadrados que Gray renueva entre 1930 y 1931- su interpretación personal de la demanda de le Corbusier hacia una precisa localización de los espacios y sistemas de almacenaje no acató el asunto sólo en términos funcionales: según Gray, «el mobiliario no debía añadirse a la arquitectura, ya que era también arquitectura» (Espegel, 2016: 128).

El concepto espacial que emerge de las casas diseñadas por Eileen Gray parece compartir algunos elementos con el espacio que Henry Urbach define como antecloset. El autor, reflexionando sobre la doble vertiente, literal y metafórica, material y lingüística, del término closet, analiza su papel espacial, y también la relación arquitectónica que vincula «closet and room» (Urbach, 1996: 63), siendo justamente el closet una «non-room» (Urbach, 1996: 63). Introduciendo el concepto espacial de ante-closet, Urbach intenta superar las dualidades tradicionales -como cierre/exposición, estar a la vista y a mano/estar escondido- que la contraposición entre room y closet sigue perpetuando. El ante-closet es el espacio expandido que está en frente del closet, un umbral in-between entre closet y room que "mediates their relation, simultaneously connecting and dissociating the two spaces» (Urbach, 1996: 65). Más allá de las implicaciones psicoanalíticas de estos asuntos -que, tal y como destaca Urbach, se pueden relacionar con los estudios de Julia Kristeva, Michel Foucault, Eve Kosofsky Sedgwick, y entrelazar con los actos y estrategias de concienciación y de empoderamiento homosexual- es interesante subrayar que se trata de espacios que se abren a posibilidades de cambios en el tiempo «by inviting acts of architectural manipulation: sliding, pressing, adjusting, grabbing» (Urbach, 1996: 72).

En años más recientes, la arquitecta Nathalie Wolberg ${ }^{7}$ en su casa-atelier en Saint Ouen (2004) supera la idea de habitación (y de espacio estancado que conlleva) realizando un entorno en el que se desenvuelven los movimientos de los cuerpos de sus usuarios y que a ellos se adapta. Se trata de un espacio doméstico concebido como un gran mueble habitable en el que un continuum espacial sin obstáculos visuales se articula y cobra vida, activado, en sus varias posibilidades de uso, a través de la manipulación y del desplazamiento de las piezas que lo componen, en el marco de un concepto de arquitectura que por su naturaleza es sensible, erótica y protésica.

Por todo lo mencionado anteriormente, «si queremos cambiar nuestra forma de pensar y proyectar viviendas» (Ábalos y Herreros, 2010: 165), tenemos que repensar 
críticamente todo lo que hemos heredado, tanto de la modernidad como de la posmodernidad, siendo conscientes de que ya no existen sistemas de pensamiento dualistas basados en la contraposición entre posturas y posicionamientos dicotómicos.

Pensar en unas viviendas marcadas por la condición femenina y desde la perspectiva de las mujeres conlleva como consecuencia no tanto y no sólo subrayar la diferencia entre una arquitectura hecha por y para mujeres y una realizada por y para hombres -diferencia que, sin embargo, resulta más que evidente- sino más bien destacar cómo un acercamiento al espacio-tiempo de la vivienda, de lo doméstico-urbano, desde las perspectivas de las mujeres abre nuevas posibilidades para todas las personas. El punto de partida ha sido cuestionar la manera en que la relación entre mujeres y espacio doméstico ha funcionado hasta ahora, evidenciando la existencia, a la vez, de unas alternativas viables que no perpetúen las rutinas y la jerarquización de los roles de género. Todavía queda mucho por hacer, la: «familia calvinista es una especie protegida por los gobiernos» (Ábalos y Herreros, 2010: 165); el modelo de ama de casa permanece en las diferencias salariales entre hombres y mujeres, en el techo de cristal que nos impide alcanzar puestos directivos en algunos sectores que los hombres monopolizan, en el estereotipo de la mujer sentimental y de la belleza que sigue todavía considerando a la mujer como un objeto, en el estereotipo de la maternidad. Sin embargo, los nuevos modos de vida de la sociedad contemporánea cuestionan la validez de los modelos tradicionales. Nuevos tipos de relaciones interpersonales y sociales y nuevos territorios, tanto simbólicos como afectivos y políticos, «al límite entre lo conocido y lo desconocido: en lo no reconocido» (Sánchez Bernal, 2012: 121) requieren otras maneras de (con) vivir. Se precisa entonces un espacio-tiempo doméstico-urbano que pueda ser adecuado para todas estas exigencias, que van más allá de lo biológico y de lo cultural, invadiendo y subvirtiendo los dos ámbitos a la vez.

Una renegociación de los estándares urbanos, edilicios y normativos, de la relación entre arquitectura y mobiliario, al igual que una valoración del papel de las cualidades táctiles, emocionales, emotivas y espirituales de los espacios arquitectónicos, son solo algunas de las posibles variables a través de las cuales poner en tela de juicio paradigmas habitacionales obsoletos. De la misma manera, la realización de una mixité funcional y social en los barrios urbanos, que garantice a la vez la presencia de unas redes de servicios accesibles sin tener que recorrer grandes distancias, favorecería la puesta en valor de los escenarios de vida cotidianos (de todas las personas y especialmente de las mujeres).

\section{REFERENCIAS Y BIBLIOGRAFÍA}

ÁbAlos, Iñaki y Herreros, Juan (2010) «Si queremos cambiar nuestra forma de pensar y proyectar viviendas». En Manuel Gausa y Ricardo Devesa (eds): Otra Mirada. Posiciones contra crónicas. Barcelona: Gustavo Gili, pp. 165-168.

Amann Alcocer, Atxu (2005) El Espacio Doméstico: La mujer y la Casa. Tesis (Doctoral). Madrid: E.T.S. Arquitectura (UPM). 
BlANCHAR, Clara (2017, febrero 6) «Pioneros de una nueva forma de acceder a la vivienda». El País. Recuperado en: https://elpais.com/ccaa/2017/02/06/catalunya/1486399374_508949.html> [fecha de consulta: 5 de noviembre 2017].

BONNEVIER, Katarina (2007) Behind straight curtains: towards a queer feminist theory of architecture. Stockholm: Axl Books.

Braidotti, Rosi (2006) Transpositions: on nomadic ethics. Cambridge, UK: Polity Press.

Colomina, Beatriz (2006) Doble exposición: arquitectura a través del arte. Tres Cantos, Madrid: Akal Ediciones (Traducción de Alfredo Brotons).

Constant, Caroline (2000) Eileen Gray. London: Phaidon Press.

Cruz, Mónica (2008) «Charlotte Perriand y el equipamiento de la habitación moderna». DEARQ: Journal of Architecture. (3): pp. 132-141.

Cuff, Dana, Higgins, Tim y DAHL, Per-Johan (2010) Backyard Homes. Los Angeles: CityLAB, UCLA Department of Architecture and Urban Design.

Duncan, Nancy (1996) «Renegotiating Gender and Sexuality in Public and Private Spaces». En Nancy Duncan (ed.): Bodyspace: Destabilizing Geographies of Gender and Sexuality. London \& New York: Routledge, pp. 127-145.

Espegel Alonso, Carmen (2016) Heroinas del espacio: mujeres arquitectos en el Movimiento Moderno. Buenos Aires: Diseño.

Fonseca Salinas, Marta (2014) «Casa sin Género». En Actas del Congreso Internacional de Vivienda Colectiva Sostenible. «I Congreso Internacional de Vivienda Colectiva Sostenible, Barcelona, 25, 26 y 27 de febrero de 2014». Barcelona: Máster Laboratorio de la Vivienda Sostenible del Siglo XXI, pp. 84-89.

Foucault, Michel (1997) «Of Other Spaces: Utopias and Heterotopias». En Neil Leach (ed.) Rethinking Architecture: A Reader in Cultural Theory. NYC: Routledge, pp. 330-336.

FriedAN, Betty (2009) La mística de la feminidad. Madrid: Cátedra (Traducción de Solimán Magalí Martínez).

Griffith Winton, Alexa (2013) «Inhabited Space: Critical Theories and the Domestic Interior». En Graeme Brooker y Lois Weinthal (eds.) The handbook of interior architecture and design. London: Bloomsbury Academic, pp. 40-49.

GutiÉrRez Mozo, María Elia (2011) «Introducción a la arquitectura y el urbanismo con perspectiva de género». Feminismo/s, N¹7, pp. 9-22.

HAYdEN, Dolores (1979) «¿Cómo sería una ciudad no sexista? Especulaciones sobre vivienda, diseño urbano y empleo». Boletín $C F+S$ 7. Octubre 1998. Recuperado en: http:/ / habitat.aq.upm.es/boletin/n7/adhay.html. El artículo contiene parte del texto de la conferencia «Planificando y diseñando una sociedad no sexista», celebrada en la Universidad de California (Los Ángeles) el 21 de abril de 1979. El texto ha sido traducido al castellano por Gloria Gómez Muñoz y Ricardo García Moreno [Fecha de referencia: 27-11-1998; fecha de consulta 1 noviembre].

Hernández Martínez, Pedro (2016) «Privacidad y publicidad en la era de las redes sociales. Conversación con Beatriz Colomina». Arquine. Recuperado en http:// www.arquine.com/privacidad-y-publicidad-en-la-era-de-las-redes-socialesconversacion-con-beatriz-colomina / [Fecha de consulta 30 de octubre 2016] 
Herreros, Juan (2010) «Espacio doméstico y sistema de objetos». En Manuel Gausa y Ricardo Devesa (eds.) Otra Mirada. Posiciones contra crónicas. Barcelona: Gustavo Gili, pp. 153-163.

LAI, Jimenez (2008) Cave House. Recuperado en http://bureau-spectacular.net/ cave-house [fecha de consulta: 13 noviembre 2017].

López SÁnchez, Rubén (2015) La disolución del espacio doméstico: el espacio-tiempo doméstico de los 'solos'. Trabajo Fin de Grado, Madrid, E.T.S. Arquitectura (UPM). Recuperado en: https://aula3tfg.files.wordpress.com/2016/02/lc3b3pezsc3a1nchez-rubc3a9n-tfg.pdf.

Markiewicz, Małgorzata (2015) Home, Domesticity, Domestication. Home Opening. Tesis Doctoral. Cracovia: Jan Matejko Academy of Fine Arts. Sculpture Department

MARINAs SÁNCHEZ, Marina (2004) «Derribando los muros del género: mujer y okupación». En Ramón Adell Argilés et alt. (eds.): Dónde están las llaves?: el movimiento okupa: prácticas y contextos sociales. Madrid: Los Libros de la Catarata, pp. 205-226.

Massey, Doreen (1992) «A place called home?». New Formations 17, pp. 3-15.

Melgarejo Belenguer, María (2011) «De Armarios y otras cosas de casas...». Feminismo/s, No.17, pp. 213-228.

MontAner, Josep María (2014) Del diagrama a las experiencias, hacia una arquitectura de la acción. Barcelona: Gustavo Gili.

Monteys, Xavier y Fuertes, Pere (2014) Casa collage: un ensayo sobre la arquitectura de la casa. Barcelona: Gustavo Gili.

Moreno Moreno, María Pura (2017) «La mujer en la creación espacial. Orígenes y prácticas». En García SÁnchez, Rafael, Cerezuela Bastida, Sergio y Jiménez GonzÁlez Francisco J. (Coords.) Architectura et Societas. Ciudad, Historia, Tiempo y Género. Cartagena: Universidad Politécnica de Cartagena, pp. 73-84.

Muxí Martínez, Zaida (2008) «Vivienda Comunitaria: Revisión Crítica», Proyectiva. Revista de Arquitectura y Proyecto Urbano, No 1, volumen 1, Medellín: Centro de Publicaciones Universidad Nacional de Colombia, pp. 16-25.

Muxí MARTínez, Zaida (2009) Recomanacions per a un habitatge no jeràrquic ni androcèntric. Barcelona: Institut Català de les Dones.

Muxí MARTínez, Zaida (2010) «Revisar y repensar el habitar contemporáneo», Revista Iberoamericana de Urbanismo, 1 marzo 2010, No 3, pp. 4-9.

Muxí Martínez, Zaida (2015) «Lilly Reich 1885-1947». Recuperado en: https:// undiaunaarquitecta.wordpress.com/2015/04/02/lilly-reich-1885-1947/ [fecha de consulta: 13 de noviembre de 2017].

Peiró, Rosana, Colomer, Concha, EscribÁ, Vicenta, Anitua, Cecilia, Artazcoz, Lucía, Borrell, Carme, et al. Grupo de género y salud pública de SESPAS (2000) «Género, armarios y cuestionarios», Gac Sanit 14, pp. 408-409.

REDACCIÓN Y AGENCIAs (2017, febrero 17) «Una cooperativa levanta en Barcelona el edificio de madera más alto de España». La Vanguardia. Recuperado en: http:/ /www. lavanguardia.com/local/barcelona/20170216/4278496793/cooperativa-barcelonalevanta-edificio-madera.html [fecha de consulta: 13 de noviembre de 2017]. 
RENDELL, Jane (2009) «Introduction: 'Gender and Space'». En Jane Rendell, Barbara Penner y Iain Borden (editado por) Gender space architecture: an interdisciplinary introduction. London: Routledge, pp. 101-111.

RyBCZYNSKI, Witold (1991) La casa: historia de una idea. Buenos Aires: Emecé.

SAlgado De la Rosa, María Asunción (2013) «Un retrato de la mujer suburbial en el cine» [en línea]. Ángulo Recto. Revista de estudios sobre la ciudad como espacio plural, vol. 5, $\mathrm{N}^{\mathrm{o}} 1$, pp. 133-148.

SÁNCHEz BeRnAL, Mónica (2012) Vivienda y mujeres: herencias, autonomías, ámbitos y alternativas espaciales. Bogotá: Universidad Nacional de Colombia. Facultad de Artes

SÁncHEz, Raúl (2017, octubre 17) «Este es el tiempo que mujeres y hombres dedican a trabajar y a cuidar». El Diario. Recuperado en: http:/ / www.eldiario.es/ nidos/brecha-domesticas-mujeres-dedican-hombres_0_691181621.html [fecha de consulta: 13 noviembre 2017].

Serrano-Lanzarote, Begoña, Mateo-Cecilia, Carolina y Rubio-Garrido, Alberto (2016) «Prácticas domésticas contemporáneas». Recuperado en: http: / / www. proyectoprogresoarquitectura.com/ [fecha de consulta: 30 de octubre 2016].

ToRRE, Susana (1999) «Expanding the Urban Design Agenda: A critique of the New urbanism». En Joan Rothschild (ed.) Design and feminism: re-visioning spaces, places, and everyday things. New Brunswick, N.J.: Rutgers University Press., pp. 3543.

TORRENT Esclapés, Rosalía (1995) «Mujeres y diseño industrial: la escuela de la Bauhaus». Asparkia: Investigació feminista, N. 5, pp. 57-70.

Urbach, Henry (1996) «Closets, Clothes, Disclosure». Assemblage, No. 30, pp. 62-73.

Valenzuela, Carolina (2004) Plantas transformables: la vivienda colectiva como objeto de intervención $A R Q$ [en línea]. Recuperado en http:/ / www.redalyc.org/articulo.oa?id=37505821 [Fecha de consulta: 2 de julio de 2017].

Valero Rodríguez, Silvia (2016) Dom[é]stica-da. Visibilizando la cotidianeidad de la mujer en el entorno doméstico contemporáneo. Trabajo Fin de Máster. Valencia: Universitat Politècnica de València.

ZAFRA, Remedios (2010) Un cuarto propio conectado (Ciber)espacio y (auto)gestión del yo. Madrid, Fórcola Ediciones.

Recibido el 20 de noviembre de 2017

Aceptado el 4 de diciembre de 2017

BIBLID [1132-8231 (2017): 113-130] 